Article

\title{
Effect of CNTs in Copper Matrix on Mechanical Characteristics and Tribological Behavior under Dry Sliding and Boundary Lubrication Conditions
}

\author{
Lin Zhao, Pingping Yao *, Haibin Zhou, Taimin Gong, Minwen Deng, Zhongyi Zhang, \\ Yelong Xiao, Hui Deng, Yang Li and Fenghua Luo *D \\ State Key Laboratory of Powder Metallurgy, Central South University, Changsha 410083, China \\ * Correspondence: yaopingpingxx@sohu.com (P.Y.); fenghualuo@csu.edu.cn (F.L.); Tel.: +86-731-88836983 (P.Y.); \\ +86-18975870913 (F.L.); Fax: +86-731-88876614 (P.Y.)
}

Received: 4 June 2019; Accepted: 5 July 2019; Published: 9 July 2019

\begin{abstract}
In the present work, the mechanical and tribological properties of carbon nanotube (CNT)-reinforced $\mathrm{Cu}$ matrix composites featuring 0-1.8 vol\% CNTs prepared by spark plasma sintering under dry sliding and boundary lubrication conditions were investigated. The results of microstructure revealed that the bonding interface in $\mathrm{Cu} / \mathrm{CNT}$ composites was very well established. Additionally, the addition of CNTs has a positive effect on improving the hardness and tensile strength of the composites, while the stress-strain response quasi-static tensile test confirms the same results. CNTs are proved to lead to certain self-lubrication. The addition of CNTs could result in decreased coefficient of friction (COF) and wear rates by reducing adhesive wear under dry sliding conditions, while the oil lubricating film was the major reason for decreased COF under boundary lubrication conditions.
\end{abstract}

Keywords: wear mechanisms; adhesive wear; CNTs; copper; load-carrying capacity; self-lubricating composites

\section{Introduction}

Copper metal matrix composites show good potential application for heavy load-carrying sliding bearing capacity [1-3]. Higher strength with enhanced heavy load-carrying capacity and self-lubricating ability is required for these high-performance $\mathrm{Cu}$ matrix composites as the service conditions become increasingly rigorous [4,5]. As we know, carbon nanotubes (CNTs) are used as ideal strengthening phases in metal matrix composites due to their unique structure and ultrahigh strength compared to metal matrix [6-11]. Many investigations concerning CNT-reinforced metal matrix composites have been performed. Some studies $[12,13]$ have shown that due to the bridging and pulling-out effect of addition CNTs in metal matrix, mechanical properties such as hardness and tensile strength are improved significantly. In copper matrix/CNT composites prepared by different methods, consistent conclusions could also be confirmed in related studies [14-16]. However, the wettability and reactivity between CNTs and $\mathrm{Cu}$ are known to be poor [17], and the interface bonding and uniform dispersion of CNTs in all methods are not very good, especially for high CNT content $[13,18]$. Thus, ultrasonic dispersion followed by mechanical ball-milling $[19,20]$ can be used to disperse CNTs in the metal matrix as a more effective technique, and spark plasma sintering (SPS) has been used since it involves rapid heating and sintering [15]. Few studies have reported on the improved interfacial characteristics of $\mathrm{Cu} / \mathrm{CNT}$ composites using SPS. CNTs are one-dimensional nanofibers with a large surface area, and $\mathrm{Cu}$ ions have larger curvature and smaller surface area. This causes geometric incompatibility between $\mathrm{CNTs}$ and $\mathrm{Cu}$ powder, which impedes even mixing of the powders into a homogeneous composite. 
Thus, it is crucial to investigate the interfacial bonding in such composites to understand the reason for the improved mechanical properties.

In addition, many studies have reported and reviewed the tribological properties of metal matrix composites. Lin [21] proved that the addition of CNTs in a volume fraction ranging from $5 \%$ to $20 \%$ would cause obvious differences in the wear mechanism under dry wear tests. Rajkumar [22] reported that the coefficient of friction (COF) and wear rate increased when the volume fraction of CNTs was beyond $15 \%$, and COF decreased under the self-lubrication effect of carbonaceous film. Tsai [23] indicated that the surface deformation of $\mathrm{Cu} / \mathrm{CNT}$ composites could be reduced by adding CNTs to the $\mathrm{Cu}$ matrix, and a carbonaceous lubricating film was formed on the contact surface during sliding. It could be concluded from the above results that the COF and wear rate of composites under dry sliding conditions decreased by adding CNTs to the Cu matrix due to positive effect on forming a carbonaceous lubricating film.

However, there are still very few studies regarding a comparison of the tribological properties and wear mechanisms of $\mathrm{Cu} / \mathrm{CNTs}$ under dry sliding and boundary lubrication conditions [16]. Moreover, few have pointed out the correlation between the tribological properties of $\mathrm{Cu} / \mathrm{CNT}$ composites and their mechanical properties. Hence, $\mathrm{Cu} / \mathrm{CNT}$ composites containing $0,0.3,0.6,1.2$, and $1.8 \mathrm{vol} . \%$ of CNTs were prepared in the present study. Then, the effect of additional CNTs on the mechanical properties and strengthening mechanism of the composites was analyzed. The tribological properties and wear mechanisms under dry sliding and boundary lubrication conditions are also discussed. Furthermore, the relationship between mechanical and tribological properties is illustrated by theoretical analyses and laboratory tests.

\section{Materials and Experimental Methods}

\subsection{Preparation of Samples}

Figure 1 shows a schematic illustration of the fabrication process of $\mathrm{Cu} / \mathrm{CNT}$ composites. First, commercially available multiwall CNTs (MWCNTs) (density $1.8 \mathrm{~g} / \mathrm{cm}^{3}$, purity $>98 \%$; Nanolab Inc., Waltham, MA, USA) prepared by chemical vapor deposition were used as raw materials. An ultrasonic dispersion method was used to disperse CNTs evenly in alcohol for $~ 60$ min until the CNT suspension was obtained $[24,25]$. Afterward, certain ratios of CNT alcohol suspension and electrolytic $\mathrm{Cu}$ powder (average size $38.3 \mu \mathrm{m}$, density $8.92 \mathrm{~g} / \mathrm{cm}^{3}$ ) were physically mixed at a speed of $280 \mathrm{rpm}$ by using a planetary ball mill for $8 \mathrm{~h}$. Brass milling balls with diameters ranging from 3.8 to $6.4 \mathrm{~mm}$ were used, and the weight ratio of brass ball to mixture was approximately 5:1. After that, the mixture was dried. A not particularly high temperature of $80^{\circ} \mathrm{C}$ and a drying time of $4 \mathrm{~h}$ in vacuum were selected to prevent the mixture from being oxidized. The $\mathrm{CNTs}$ after ultrasonic dispersion and the $\mathrm{Cu} / \mathrm{CNT}$ composite powders used to prepare the specimens are shown in Figure 1. Most of the CNTs could be seen to be uniformly attached to the surface of the $\mathrm{Cu}$ powder or embedded closely in the $\mathrm{Cu}$ particle surface under magnification. Subsequently, the dried mixed powders were compacted at a pressure of $400 \mathrm{MPa}$ and then processed by SPS in a graphite die at $800^{\circ} \mathrm{C}$ for $45 \mathrm{~min}$ under pressure of $40 \mathrm{MPa}$ in an argon atmosphere. Finally, the specimens were prepared after cooling in water at a cooling rate of approximately $100^{\circ} \mathrm{C} / \mathrm{min}$.

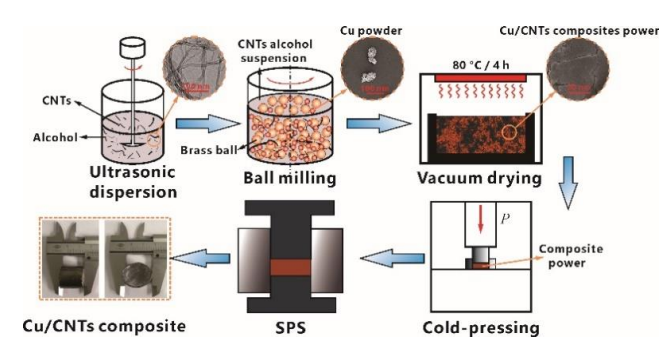

Figure 1. Schematic illustration of the fabrication process of $\mathrm{Cu} / \mathrm{carbon}$ nanotube (CNT) composite. 


\subsection{Mechanical and Tribological Properties Test}

The Archimedes method, following Standard GB/T 1423-1996, was used to measure the density of the composites. The Instron 3369 machine was used to measure the tensile strength of the specimens with a strain rate of $2.1 \times 10^{-3} \mathrm{~s}^{-1}$ (crosshead speed, $1 \mathrm{~mm} / \mathrm{min}$ ). The tensile specimens were machined by wire electrode cutting with a cross-section of $2 \times 2 \mathrm{~mm}^{2}$ and a gauge length of $8 \mathrm{~mm}$. Vickers hardness test was selected to evaluate the hardness of the $\mathrm{Cu} / \mathrm{CNT}$ composites. A frictional test was carried out using a ball-on-block tribometer (Figure 2) under dry sliding and boundary lubrication conditions, where predrip oil was used to ensure boundary lubrication. A steel ball bearing (AISI52100; 0.95-1.05 C, 0.20-0.40 Mn, 0.15-0.35 Si, 1.30-1.65 Cr; $\mathrm{S} \leq 0.020, \mathrm{P} \leq 0.027, \mathrm{Mo} \leq 0.10, \mathrm{Ni} \leq 0.30, \mathrm{Cu} \leq$ $0.25, \mathrm{Ni}+\mathrm{Cu} \leq 0.50$ ) hardened to $63-65 \mathrm{HRC}$ with a $9.5 \mathrm{~mm}$ diameter was selected as a testing ball. The samples were ground and polished using $\mathrm{SiC}$ grit paper until a surface roughness (Ra) of $1.2 \mu \mathrm{m}$ was achieved. The specimens were subsequently cleaned using anhydrous alcohol. A constant normal load with a range of 5 to $60 \mathrm{~N}$, a fixed sliding distance of $5 \mathrm{~mm}$, a reciprocating speed of $600 \mathrm{rpm}$ $(0.1 \mathrm{~m} / \mathrm{s})$, and a test time of $900 \mathrm{~s}$ were programmed during testing. Five indentations under same conditions were performed for each composite.

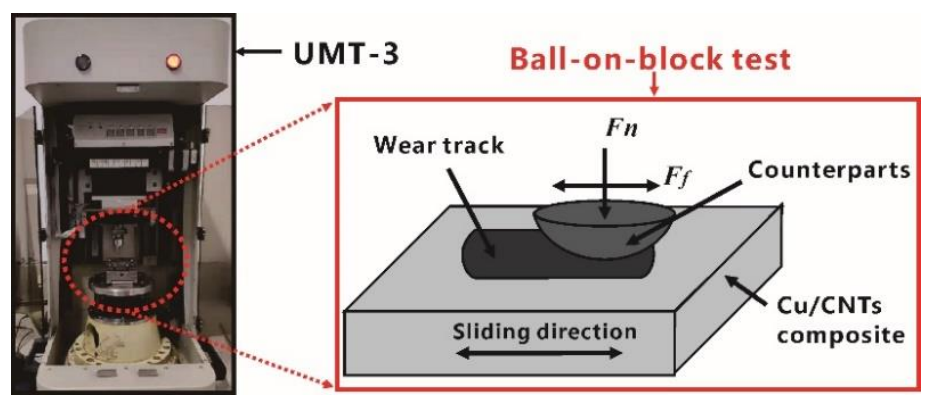

Figure 2. Schematic illustration of ball-on-block tribometer.

The microstructure of the specimens and the worn surface of the wear tracks were characterized by scanning electron microscopy (SEM; Nova NanoSEM230, FEI, Hillsboro, OR, USA) and transmission electron microscopy (TEM; JEM-2100F, JEOL, Tokyo, Japan) at a working voltage of $200 \mathrm{kV}$. The average length $(\mathrm{mm})$ and cross-sectional area $\left(\mathrm{mm}^{2}\right)$ of wear tracks were measured by a 3D surface profilometer (Nano Map 500-LS, AEP Technology, Braselton, GA, USA), then multiplied to get the wear volume. Then the wear rate was calculated utilizing Equation (1)

$$
W=V /(f \cdot L)
$$

where $W$ is the wear rate, $V$ is the wear volume $\left(\mathrm{mm}^{3}\right), f$ is the friction force $(\mathrm{N})$, and $L$ is the sliding distance $(\mathrm{m})$ of specimen.

\section{Results and Discussion}

\subsection{Microstructure of $\mathrm{Cu} / \mathrm{CNT}$ Composites}

It could be seen from the metallographs that pure $\mathrm{Cu}$ is more compact than $\mathrm{Cu} / 0.6 \mathrm{CNT}$ composite (composition: $99.4 \mathrm{vol} \% \mathrm{Cu}$ and $0.6 \mathrm{vol} \% \mathrm{CNT}$, referred to as $\mathrm{Cu} / 0.6 \mathrm{CNT}$ ) and twin crystals were seen in both, as shown in Figure 3a,b. Note that the dark regions in Figure 3b, corresponding to pores, indicate that porosity increases after the addition of CNTs. Due to the scale difference, the nanoscale CNTs could not be clearly observed. However, the uniform homogeneous distribution of the metallographic structure of $\mathrm{Cu} / \mathrm{CNT}$ composites suggests that CNTs are probably uniformly distributed in composites [26,27]. In order to clearly describe the effect of additional CNTs on the density of $\mathrm{Cu} / \mathrm{CNT}$ composites, the relative densities of pure $\mathrm{Cu}$ and $\mathrm{Cu} / \mathrm{CNT}$ composites are shown in 
Figure 3c. The density decreased as the volume fraction of CNTs increased. The relative density of the $\mathrm{Cu} / \mathrm{CNT}$ composite was lower than that of pure $\mathrm{Cu}$, as expected.
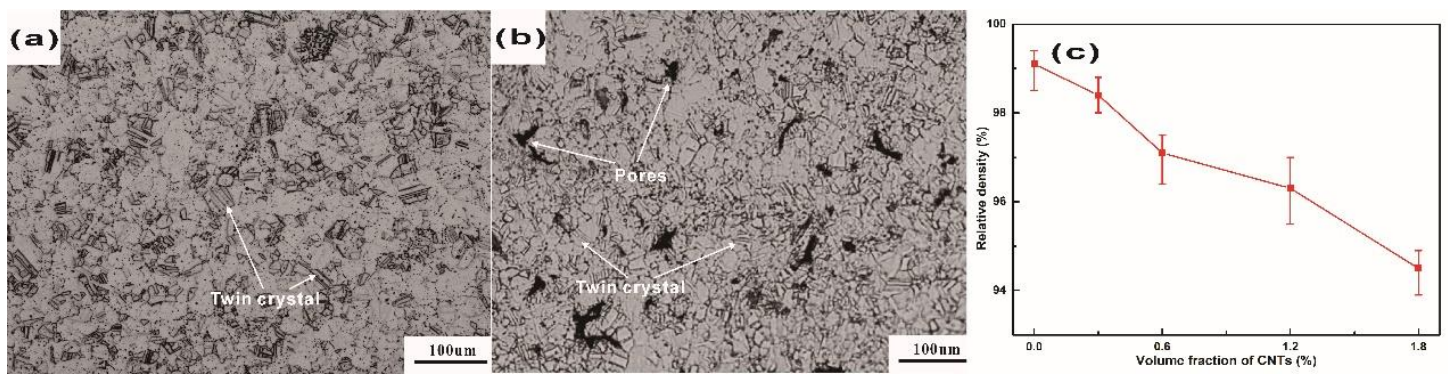

Figure 3. Typical metallographs of (a) pure $\mathrm{Cu}$ and (b) $\mathrm{Cu} / 0.6 \mathrm{CNTs}$ and (c) relative density of $\mathrm{Cu} / \mathrm{CNT}$ composite.

Figure 4 shows TEM images of the $\mathrm{Cu} / \mathrm{CNT}$ composite. As shown in Figure $4 \mathrm{a}$, the SEM image demonstrates the existence of a transitional interfacial layer at the interface bonding region and the damaged CNTs after ball-milling. In order to determine the microstructure of the interfacial layer, high-resolution TEM (HRTEM) images and corresponding energy-dispersive X-ray spectroscopy (EDS) analysis were carried out. As shown in Figure $4 b$, the grain boundary can be clearly observed. The interfacial layer zone displays the lattice fringes of the $\mathrm{Cu}-(200)$ and $\mathrm{Cu}-(111)$ faces with spacing of 0.18 $\mathrm{nm}$ and $0.20 \mathrm{~nm}$, as shown in the fast Fourier-transform (FFT) image (Figure 4c). This suggests that some $\mathrm{Cu}$ atoms appear among the CNTs, presumably causing deformation of the CNTs and forming a coherent lattice with them [26,27]. The EDS analysis (marked B in Figure 4a) shown in Figure 4d also confirms that the element composition of $\mathrm{Cu}$ and $\mathrm{C}$ did not undergo a component mutation, but there was a gradient change in the region of the CNT and $\mathrm{Cu}$ interface, which is in agreement with HRTEM results. Therefore, it can be speculated that CNTs and Cu matrix have a good bonding interface. Generally, the ball-milling process is able to destroy the structures of the outer surfaces of CNTs via repetitive deformation, cold welding, and fracturing of the mixed powders [24,28]. However, carbon bonds were broken in the prism planes of the outer surfaces of damaged CNTs as shown in Figure $4 \mathrm{a}$. As a result, this promotes the diffusion of $\mathrm{Cu}$ to form good interfacial bonding. Hence, a strong interface bonding that can transfer loads effectively is a significant factor in improving the mechanical properties of the composites [29].
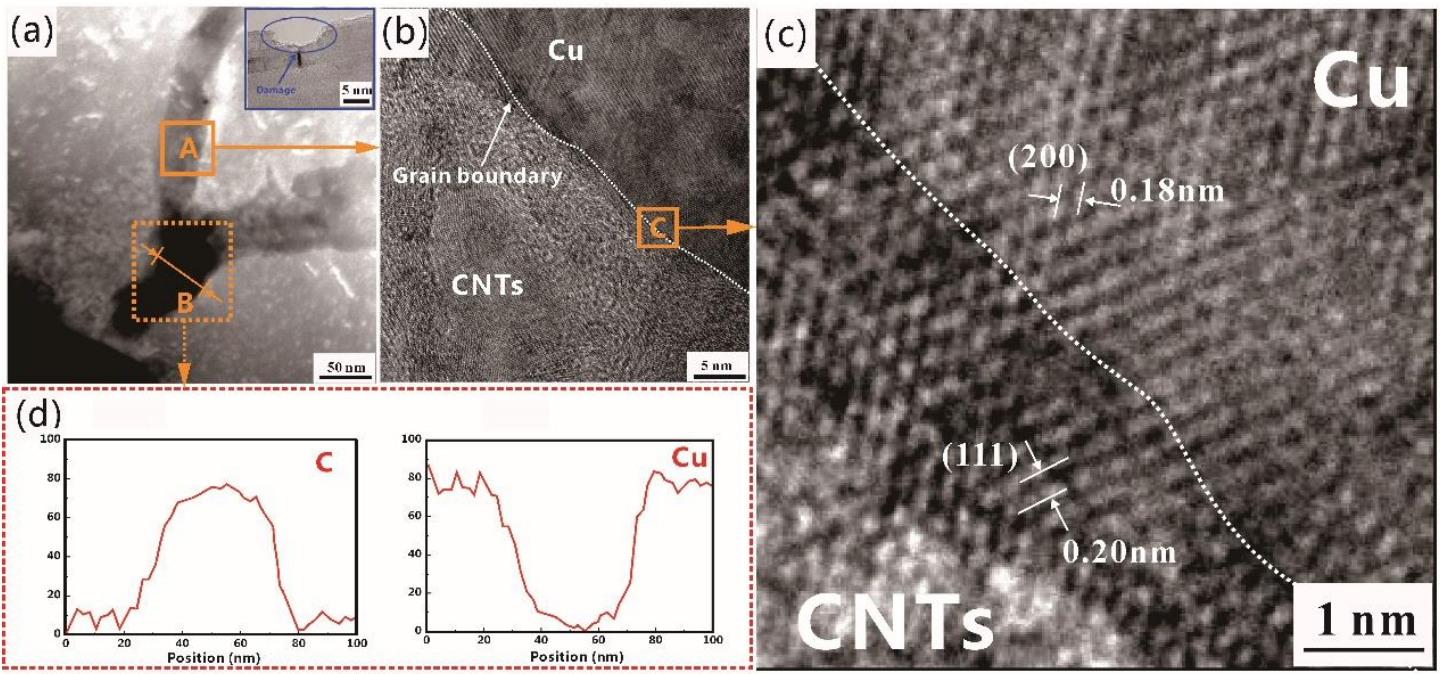

Figure 4. TEM images of $\mathrm{Cu} / \mathrm{CNT}$ composite: (a) interface bonding of $\mathrm{Cu}$ and $\mathrm{CNTs}$, (b) high-resolution TEM (HRTEM) image of highlighted region A, (c) HRTEM image of highlighted region C, and (d) energy-dispersive $\mathrm{x}$-ray spectroscopy (EDS) line-scanning results of region $\mathrm{B}$. 


\subsection{Mechanical Properties}

Figure 5 a shows the typical quasi-static stress-strain curves of pure $\mathrm{Cu}$ and $\mathrm{Cu} / 0.6 \mathrm{CNT}$ composite. All the specimens mentioned in this paper presented the similar mechanical responses to with that seen in Figure 5a when exposed to quasi-static loads. It can be seen from the curve shape that the specimens went had gone through the elastic deformation stage and yield stages in the tensile test. However, a much higher modulus and larger failure strain are observed in $\mathrm{Cu} / 0.6 \mathrm{CNT}$ composite. CNTs with high strength and modulus take loads and inhibit the deformation of the material during the process of tensile strength testing. Therefore, $\mathrm{Cu} / \mathrm{CNT}$ composites present higher modulus, tensile strength, elongation, and failure strain than pure $\mathrm{Cu}$. The tensile strength and Vickers hardness of the specimens are shown in Figure 5b. First, it can be observed that all composites show higher tensile strength and Vickers hardness than pure $\mathrm{Cu}$; both of them increased first and then decreased as the content of CNTs increased, such similar phenomena were observed in aluminum /CNTs composites [30]. Therefore, the addition of CNTs can enhance the tensile strength and Vickers hardness of copper matrix. The $\mathrm{Cu} / 0.6 \mathrm{CNT}$ composite exhibited higher tensile strength (308 MPa) and Vickers hardness (106 Hv) than pure $\mathrm{Cu}$. A lower relative density but a higher tensile strength and Vickers hardness for $\mathrm{Cu} / \mathrm{CNT}$ composites can be ascribed to the high stiffness and strength of CNTs. When the external loads act on the $\mathrm{Cu} / \mathrm{CNT}$ composites, it is easy to transfer through the bonding interface, consequently improving the hardness and tensile strength of the composite material with a uniform distribution of CNTs. The significantly increased strength also indicates that the composites were successfully fabricated by this combination process. However, a further increase in CNT content led to increased porosity, as well as the possibility of CNTs agglomerating in the specimens. The rising porosity lowered the hardness, whereas the agglomeration of CNTs reduced the contact area and weakened the interface bonding between CNTs and matrix, inevitably resulting in a decline in tensile strength.
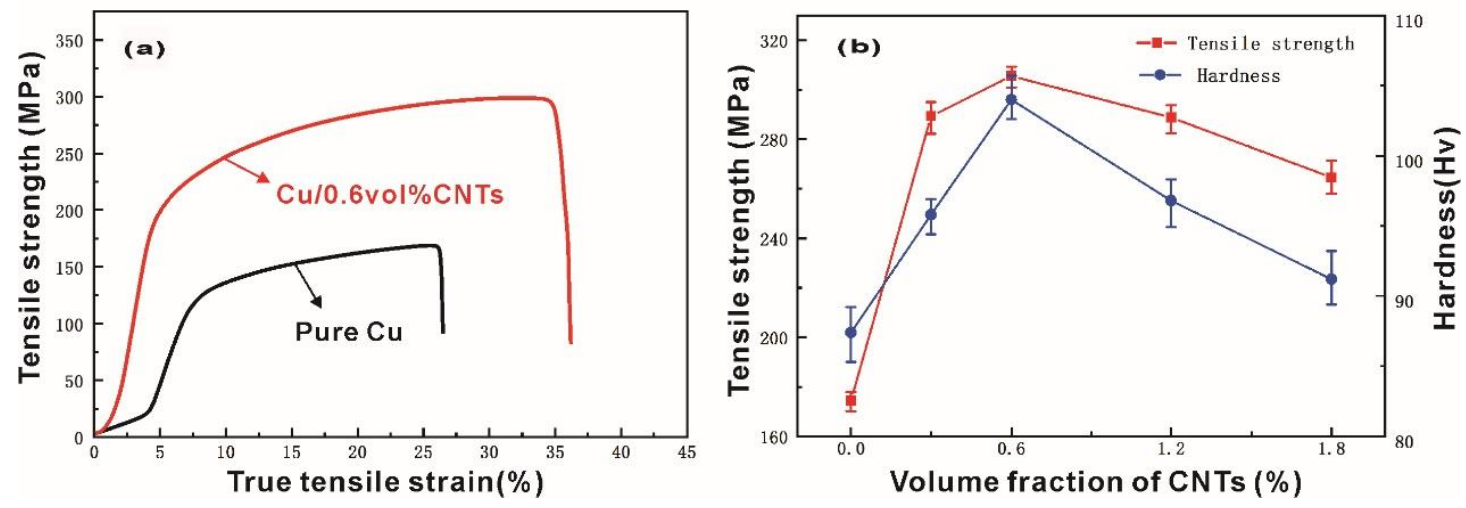

Figure 5. Mechanical properties of pure $\mathrm{Cu}$ and $\mathrm{Cu} / \mathrm{CNT}$ composites: (a) typical quasi-static stress-strain curves and (b) tensile strength and Vickers hardness.

The typical fractured surfaces of as-prepared composites after tensile tests are shown in Figure 6. The toughening nest, which tends to gradually increase in size as CNTs increase, is found in the fracture morphology of all $\mathrm{Cu} / \mathrm{CNT}$ composites, implying that ductile fracture occurs during the test. In the enlarged fracture morphology, the CNT clusters are observed locally in the toughening nest and pores. Moreover, many single CNTs are attached to the surface of the $\mathrm{Cu}$ matrix, and some $\mathrm{Cu}$ particles are embedded in CNTs clusters, as shown in Figure 6d. It can be predicted that the amount of pull-out CNTs increases as the volume fraction increases, such phenomenon was also found in previous studies $[14,15,28]$. In addition, a CNT bridge can be observed. When the matrix reached its ultimate heavy load capacity during the test, CNTs also played a load-bearing role by suppressing the matrix crack extension, thus promoting crack deflection [29]. This is beneficial to improve the heavy load-carrying capacity of the material with higher strength. When the volume fraction is greater than or equal to $1.2 \%$, CNT clusters appear in the fracture, indicating that the CNTs are poorly dispersed in 
the matrix, leading to weak bonding in the composite. It is worth pointing out that CNT clusters and degraded bonding were the main reasons for the decline in tensile strength [9].
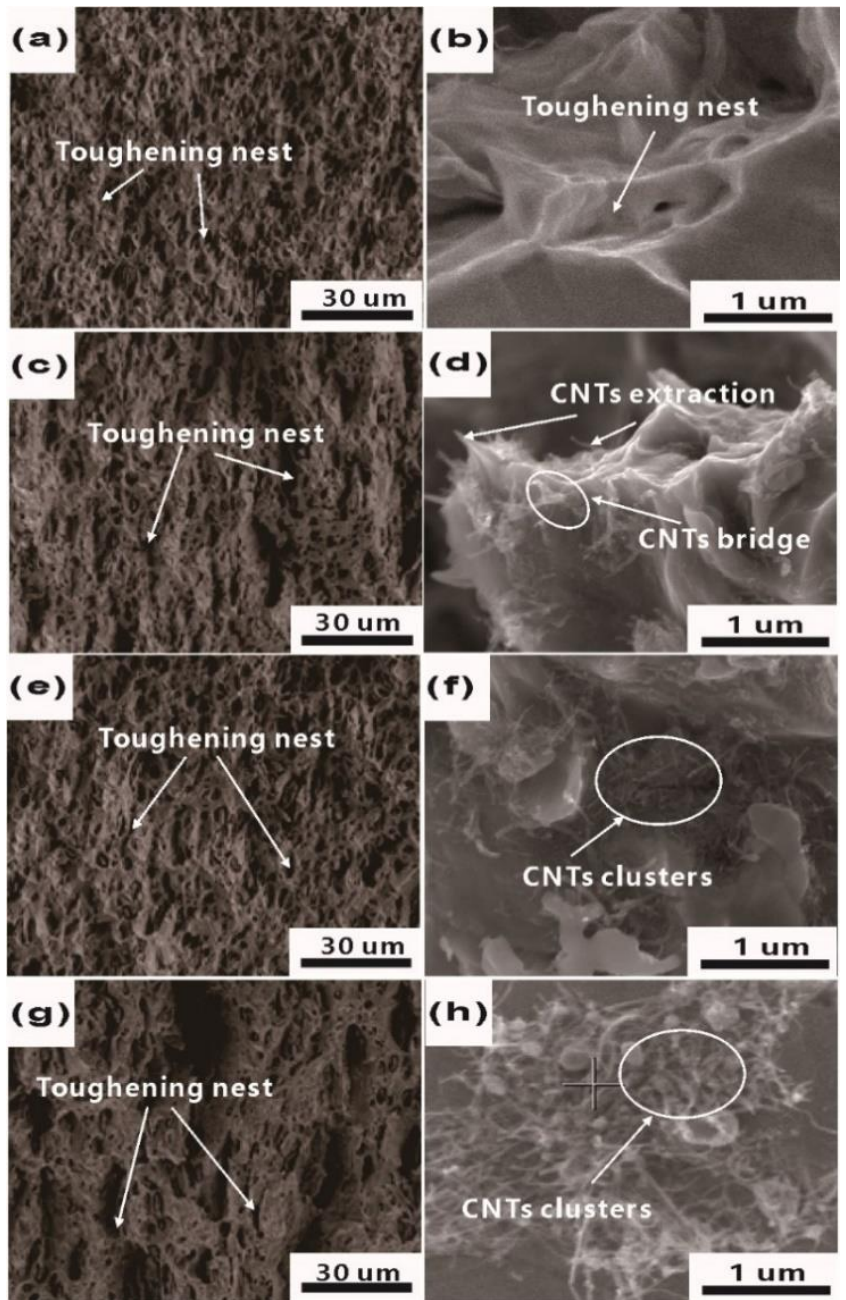

Figure 6. SEM micrographs of fractured surfaces of $\mathrm{Cu} / \mathrm{CNT}$ composites containing $(\mathbf{a}, \mathbf{b})$ 0.3, (c,d) 0.6, $(\mathbf{e}, \mathbf{f}) 1.2$, and $(\mathbf{g}, \mathbf{h}) 1.8$ vol.\% CNTs after tensile tests.

Generally, Orowan strengthening and the load-transfer effect are proposed to explain the strengthening phenomenon observed in particle-reinforced metal matrix composites [29]. Combining TEM observations with mechanical properties, the improvement in $\mathrm{Cu} / \mathrm{CNT}$ composites could be due to two points: (a) homogeneous dispersion of CNTs in the Cu matrix. CNTs dispersed in composites can effectively hinder grain growth during the heating process, thus improving the properties of the composite. (b) Strong interfacial bonding strength can effectively transfer loads when the external loads work.

\subsection{Tribological Properties under Dry Sliding and Boundary Conditions}

Figure 7 shows the average COF and corresponding wear rate of the specimens with a load of 10 $\mathrm{N}$ under dry sliding conditions. It can be seen that the $\mathrm{Cu} / 0.6 \mathrm{CNT}$ composite exhibited the lowest $\mathrm{COF}$ and wear rate, which shows that it has the best antiwear ability. The COF and wear rate declined when the fraction of added CNTs was lower than $0.6 \mathrm{vol} \%$ but slowly increased when the proportion went above $0.6 \mathrm{vol} \%$. Note that the change in $\mathrm{COF}$ and wear rate is contrary to that in hardness and tensile strength (see Figure $5 \mathrm{~b}$ ) as the volume fraction of CNTs increases, indicating that the tribological behavior is closely related to the mechanical properties of composites. The increased hardness will 
lead to a decreased direct metal contact area. Thus, the $\mathrm{Cu} / 0.6 \mathrm{CNT}$ composites with the highest hardness show the lowest COF. Moreover, according to the test standard variation, pure $\mathrm{Cu}$ presents higher fluctuations in COF than other composites in this work. This can be ascribed to severe adhesion at the two contact surfaces and work-hardening of pure $\mathrm{Cu}$. However, as more CNT particles are incorporated into the $\mathrm{Cu}$ matrix, the average $\mathrm{COF}$ of $\mathrm{Cu} / \mathrm{CNT}$ composite becomes remarkably lower and more stable during tests. The positive effect of the improved mechanical properties by adding CNTs could lead to lower wear track depth during tests [31]. As the CNT content increases, the direct contact area on the counterpart will be reduced during the friction test. Consequently, the probability of adhesive wear will decrease. What is more, the addition of CNTs may enable the composite to have a certain self-lubricating capacity [32]. All of these factors confirm that the addition of CNTs can improve antiwear ability and reduce the tendency of adhesive wear [12,32,33]. Furthermore, the addition of CNTs may give the material a certain self-lubricating capacity. However, more CNTs added into the $\mathrm{Cu}$ matrix leads to more CNT clusters in the composite, which reduces the heavy load capacity and wear resistance.

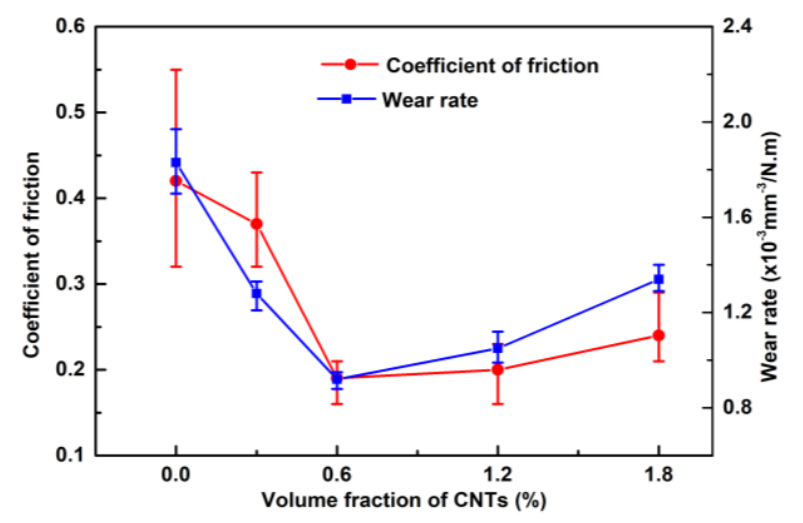

Figure 7. Coefficient of friction (COF) and wear rates of pure $\mathrm{Cu}$ and $\mathrm{Cu} / \mathrm{CNT}$ composites with a pressure of $10 \mathrm{~N}$ under dry sliding conditions.

Figure 8 shows the worn surfaces. The adhesion spalling pits (Figure 8a) were characterized as typical features in pure $\mathrm{Cu}$, due to strain-hardening caused by the reciprocating friction force, and cracks induced worse plastic deformation ability. At the same time, friction led to the formation of fresh surfaces and the occurrence of adhesive wear, which was observed in other $\mathrm{Cu}$ matrix composites [2,3]. With increased CNTs, the worn surfaces became quite different (see Figure 8b-e). Adhesion spalling pits gradually disappeared while cracks, grooves, and fatigue pits were found on the worn surface. Compared to other $\mathrm{Cu} / \mathrm{CNT}$ composites, the worn surface of $\mathrm{Cu} / 0.6 \mathrm{CNT}$ composites in Figure $8 \mathrm{c}$ presents typical features of grooves, quite different from those of $\mathrm{Cu} / 0.3 \mathrm{CNT}$ composites shown in Figure $8 \mathrm{~b}$. The grooves were believed to be generated by hard asperities on the counterpart and reciprocal wear debris plowing and grinding over the composite. Because of the improved mechanical properties, enhanced adhesive resistance, and plastic deformation resistance while adding CNTs, the wear mechanism changed gradually from adhesive to plow wear. It could be observed that the worn surfaces in Figure 8d,e are rougher and the grooves are deeper and wider than those in Figure 8c. The fatigue pits in Figure 8e indicate the main wear mechanism by plow wear and fatigue wear, and the decreased mechanical properties caused by the high CNT content may be the key reason for this phenomenon. Therefore, it can be confirmed again that the addition of CNTs should not exceed 0.6 vol\%. Figure $8 \mathrm{f}$ show the higher magnification worn surface of $\mathrm{Cu} / \mathrm{CNTs}$ composite, and the EDS results of the marked region in Figure $8 \mathrm{f}$ indicate that it contains a higher content of carbon than other regions, and the morphology of this strip is similar to that of added CNTs. Since the composite consists only of $\mathrm{Cu}$ and CNTs, it can be confirmed that thin strips of CNTs can obviously be seen to be distributed parallel to the sliding direction. Therefore, it is difficult for cracks and large debris drops to form, resulting in less wear [34]. 


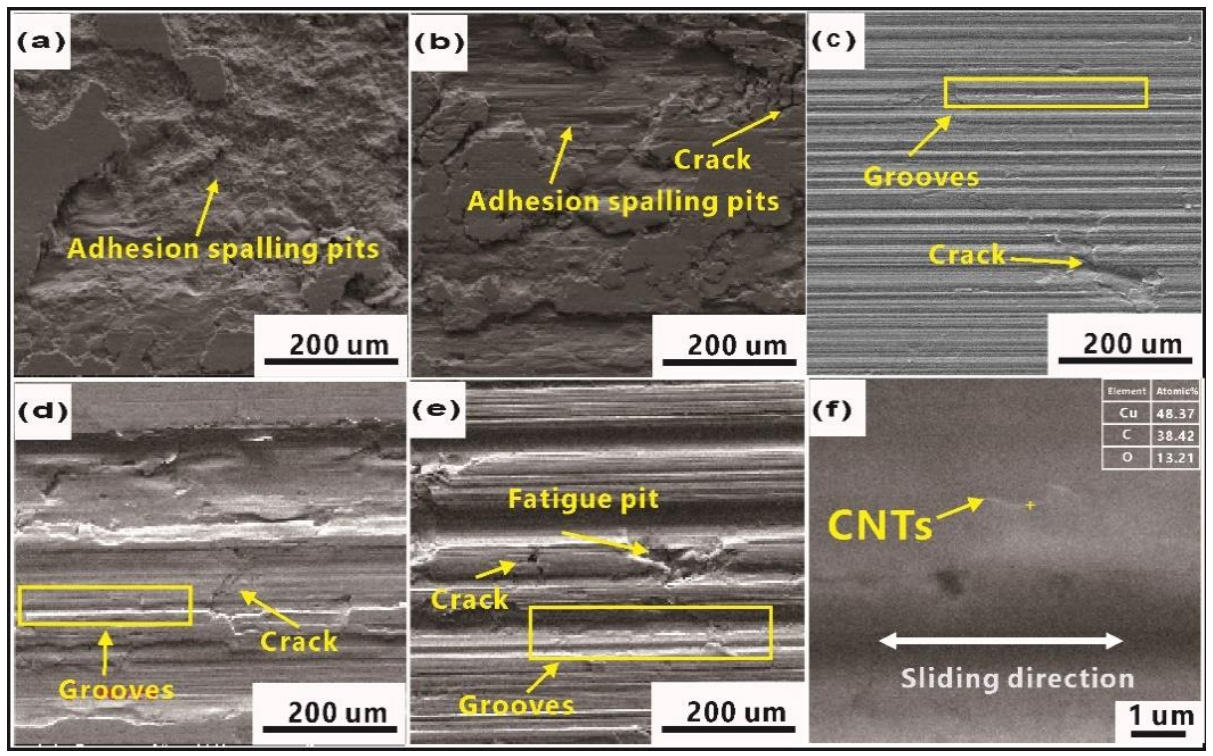

Figure 8. SEM images of worn surface under dry friction conditions of $\mathrm{Cu} / \mathrm{CNT}$ composites containing: (a) 0, (b) 0.3, (c) 0.6, (d) 1.2, and (e) 1.8 vol.\% CNTs and (f) highly magnified image of worn surface.

Figure 9 shows the average $\mathrm{COF}$ curves of $\mathrm{Cu} / \mathrm{CNT}$ composites with a pressure range from $5 \mathrm{~N}$ to $60 \mathrm{~N}$ under boundary conditions. Obviously, the COF of the composites first decreased and then increased as the volume fraction of CNTs increased. The $\mathrm{Cu} / 1.2 \mathrm{CNT}$ composite exhibited the lowest $\mathrm{COF}$. Compared to the average COF under dry test conditions, the variation trend of the friction curve was basically the same, and the average COF decreased significantly as expected, but the CNT content in the composite with the lowest COF changed from 0.6 to $1.2 \mathrm{vol} \%$. The reduced COF with this range of CNTs could be attributed to the lubricating oil film at the sliding surface, which can effectively prevent direct contact between two sliding surfaces. There may also be two other factors: first, a positive effect on the mechanical properties with a lower CNT content might have an important role in the descent stage of COF. Second, adding excessive CNTs deteriorates mechanical properties, such as the heavy load capacity and wear resistance, thus raising the COF in the ascent stage. Additionally, the pores to store lubricating oil might be the major reason for the lowest $\mathrm{COF}$ change from $\mathrm{Cu} / 0.6 \mathrm{CNT}$ to $\mathrm{Cu} / 1.2 \mathrm{CNT}$ composites.

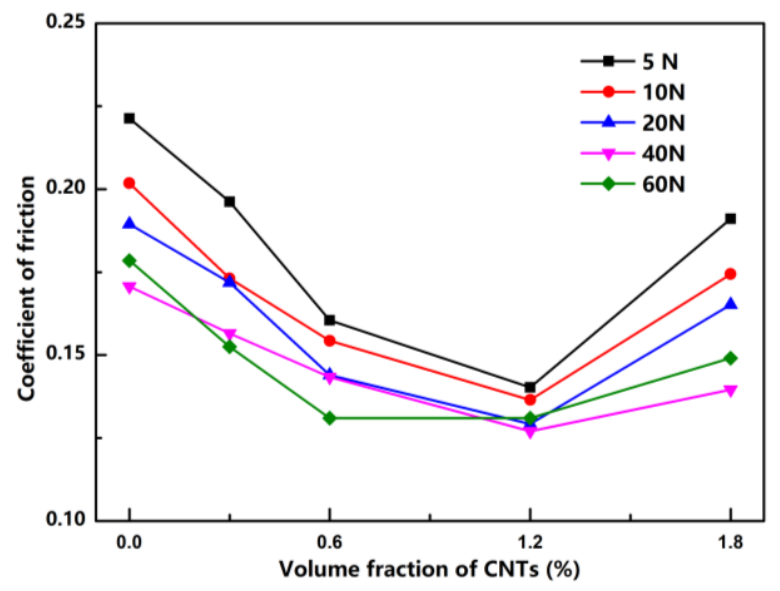

Figure 9. Average $\mathrm{COF}$ of pure $\mathrm{Cu}$ and $\mathrm{Cu} / \mathrm{CNT}$ composites under different loading pressures and boundary lubrication conditions. 
According to the adhesive theory [35], friction force $(f)$ is composed of shear force on the adhesive part of the shear surface and shear force on the lubricating film, and can be expressed as Equation (2). The load $\left(F_{n}\right)$ is supported by contact of the microconvex body and lubricating film, and can be expressed as Equation (3):

$$
\begin{gathered}
f=A_{r}\left[\alpha \tau_{b}+(1-\alpha) \tau_{f}\right] \\
F_{n}=A_{r}\left[\alpha \delta_{s}+(1-\alpha) \delta_{s f}\right]
\end{gathered}
$$

where $f$ is the friction force, $A_{r}$ is the total actual area under load, $\alpha$ is the percentage of direct metal contact area over total area under load, $\tau_{b}$ is the shear strength of soft metals, $\tau_{f}$ is the shear strength of lubricant film, $F_{n}$ is the load, $\delta_{s}$ is the compressive yield strength limit of the material, and $\delta_{s f}$ is the yield limit of lubricant film. Then the $\mathrm{COF}(\mu)$ can be written as

$$
\mu=\frac{f}{F_{n}}=\frac{\alpha \tau_{b}+(1-\alpha) \tau_{f}}{\alpha \delta_{s}+(1-\alpha) \delta_{s f}}
$$

Under oil lubricating conditions, $\alpha$ is very small, and $\delta_{s}$ and $\delta_{s f}$ are almost equal, so $\mu=\tau_{f} / \delta_{s}$. Generally, the shear strength of lubricating film is much smaller than that of metal, so the COF under oil lubricating conditions is much smaller than that of dry friction. In addition, it is worth noting that the role of improved mechanical properties is non-negligible in the decrease of $\alpha$, which reduces the COF. Otherwise, the COF will rise. This explains the different COF under oil lubricating conditions with different volume fraction CNTs from a theoretical perspective.

The worn surface topography of $\mathrm{Cu} / \mathrm{CNT}$ specimens under oil lubricating conditions is shown in Figure 10. It can be seen from Figure 10a-e that the worn surfaces of the $\mathrm{Cu}$ composites with different volume fractions of CNTs are totally different. However, the change trend is similar to the dry friction condition except for the obvious adhesive wear feature. Composites with CNTs in the range of 0.3 to $1.2 \mathrm{vol} \%$ (see Figure 10b-d) have better heavy load capacity than other $\mathrm{Cu} / \mathrm{CNT}$ composites under the current working conditions. Too much or too little CNT content is detrimental to the tribological properties, leading to severe plastic deformation, as indicated by a large number of cracks or fatigue pits, seen in Figure 10a,e. Thin strips of CNTs are seen to be distributed parallel to the sliding direction in Figure 11f.

To better understand how CNTs affect the COF, wear rate, and wear mechanism of composites, we used a schematic illustration of wear mechanism of $\mathrm{Cu} / \mathrm{CNT}$ composites under dry friction and boundary lubrication conditions, shown in Figure 11a,b, respectively. Under the same loading pressure ( $F_{n}$ in Figure 11) and dry friction conditions, as shown in Figure 11a, the depth of the counterpart pressed into the composite (h in Figure 11) and the contact area will decrease due to the improved mechanical properties by adding CNTs, thus reducing the friction force (f), which prevents motion. Therefore, the $\mathrm{COF}$ and wear rate of $\mathrm{Cu} / \mathrm{CNT}$ composite were smaller than those of pure $\mathrm{Cu}$. Under boundary lubrication conditions, as shown in Figure 11b, the oil lubricating film carried most of the load and its low shear strength might be the major reasons for the lower COF and wear rate than those of the dry friction condition, and the mechanical properties had similar effects on $\mathrm{h}$ and the contact area under dry friction conditions. It would not be repeated again here. 


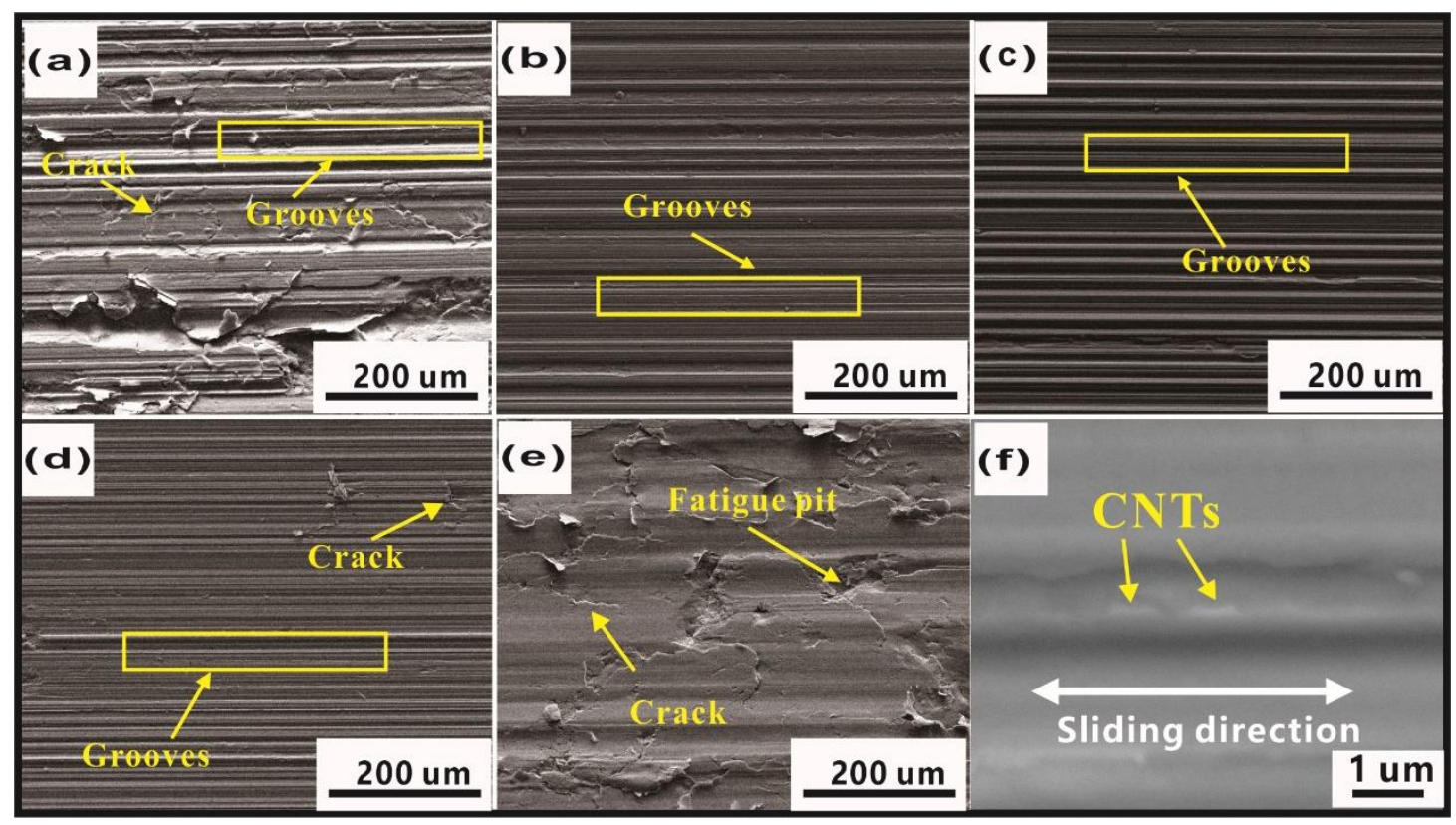

Figure 10. SEM images of worn surface under boundary lubrication conditions of $\mathrm{Cu} / \mathrm{CNT}$ composites containing: (a) 0, (b) 0.3, (c) 0.6, (d) 1.2, and (e) 1.8 vol.\% CNTs under a load of $40 \mathrm{~N}$ and (f) highly magnified image of typical grooves.
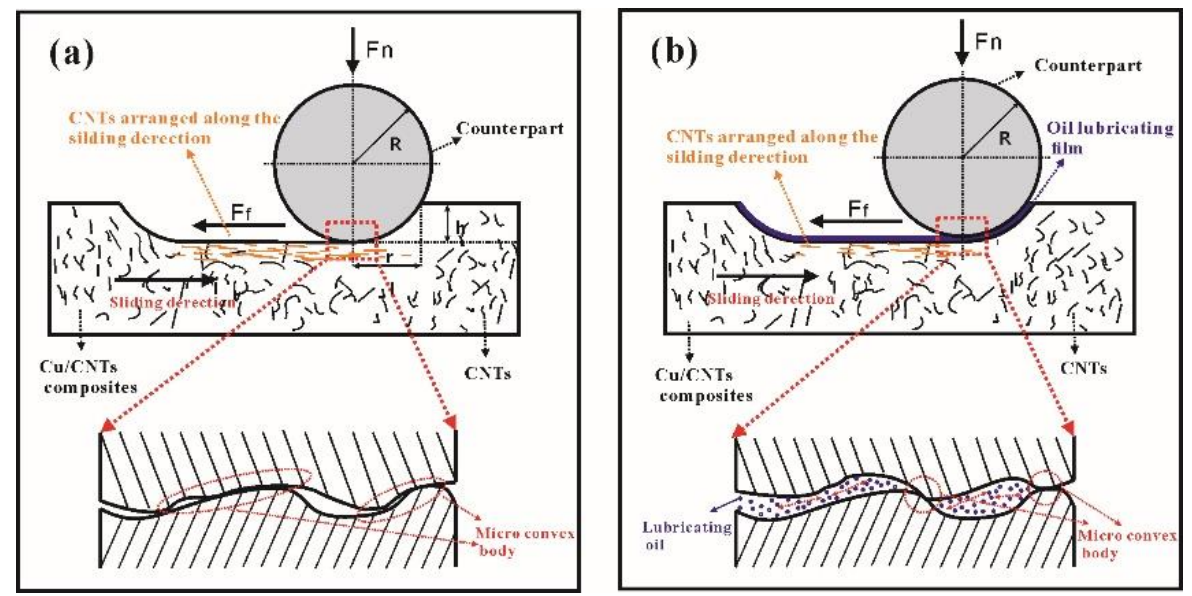

Figure 11. Schematic illustration of wear mechanism: (a) dry friction condition and (b) boundary lubrication condition.

In terms of wear mechanism, it is well known that there are many microconvex bodies on the contact surface, and, under dry friction conditions, the pressure load causes them to have direct contact, as shown in the magnified image in Figure 11a. Then the reciprocating $F_{\mathrm{f}}$ causes severe plastic deformation of the microconvex bodies. This then leads to the initiation, development, and fracture of cracks, and thus produces wear debris. It is easy to form adhesive pits because of the obvious adhesive tendency of the counterpart and pure $\mathrm{Cu}$, while in $\mathrm{Cu} / \mathrm{CNT}$ composites, the CNTs on the worn surface were arranged along the sliding direction with the plastic deformation, as shown in Figure 11a. This may be the main reason for the decreased adhesive wear tendency, resulting in lower $\mathrm{COF}$ and better wear resistance. Compared to the adhesive mechanism in pure $\mathrm{Cu}$, plowing is the main wear mechanism in $\mathrm{Cu} / \mathrm{CNT}$ composites, caused by the reciprocating motion of the microconvex bodies and the third body on the worn surface. Under boundary lubrication conditions, the existence of the lubricating oil film greatly reduces the microconvex body direct contact area, as shown in Figure $11 \mathrm{~b}$. This avoids the possibility of adhesive wear and greatly reduces the plastic deformation 
of the composite under Ff compared with that under dry friction. Thus, the phenomenon of parallel arrangement of CNTs along the sliding direction was less than in dry friction conditions, as shown in Figure 11b. Therefore, both pure $\mathrm{Cu}$ and $\mathrm{Cu} / \mathrm{CNT}$ composites are dominated by the plow wear mechanism. It is also worth pointing out that the worn surface topography results in this study are consistent with the above wear mechanism, and the volume fraction of CNTs is closely related to the significance of the wear mechanism.

\section{Conclusions}

$\mathrm{Cu} / \mathrm{CNT}$ composites were prepared by SPS combined with ultrasonication treatment and mechanical ball-milling before consolidation. The effects of CNTs on mechanical and tribological properties were investigated. The following conclusions can be drawn.

(1) Uniformly dispersed carbon nanotubes in the $\mathrm{Cu}$ matrix can be obtained through ultrasonic dispersion and mechanical ball-milling. The relative density of the $\mathrm{Cu} / \mathrm{CNT}$ composite was close to that of pure $\mathrm{Cu}$.

(2) The addition of CNTs can effectively improve the mechanical properties of the composites. $\mathrm{Cu} / 0.6 \mathrm{CNTs}$ exhibited the best hardness and tensile strength. The CNTs and $\mathrm{Cu}$ matrix were well bonded at the interface, with $\mathrm{Cu}$ atoms appearing in the CNTs locally.

(3) The lowest $\mathrm{COF}$ and wear rates of $\mathrm{Cu} / \mathrm{CNT}$ composites were obtained when the CNTs equaled 0.6 vol. $\%$ under dry sliding conditions and 1.2 vol. $\%$ under boundary lubrication conditions. The CNTs also had certain self-lubricating properties.

(4) The wear mechanisms under dry friction and boundary lubrication conditions were different. The CNTs mainly reduced COF and wear rates by reducing the adhesive wear tendency under dry friction conditions, while the oil lubricating film was the major reason for the decreased COF under boundary conditions. Composites with CNT volume fraction between $0.6 \%$ and $1.2 \%$ exhibited the best tribological performance and heavy load carrying capacity.

Author Contributions: Conceptualization, L.Z.; methodology, T.G.; software, H.Z.; validation, L.Z., Y.X. and P.Y.; formal analysis, L.Z.; investigation, L.Z. and H.D.; resources, P.Y.; data curation, L.Z., Z.Z. and M.D.; writing—original draft preparation, L.Z.; writing—review and editing, L.Z., Y.L. and F.L.; visualization, L.Z. and H.Z.; supervision, P.Y.; project administration, L.Z.; funding acquisition, P.Y.

Funding: This research was funded by the National Nature Science Foundation of China, [grant numbers 51475476].

Acknowledgments: Thanks for Xiaoqin Ou from Central South University, China and Jiayu Zhao for their kind contributions.

Conflicts of Interest: The authors declare no conflict of interest.

\section{Nomenclature}

$\begin{array}{ll}W & \text { wear rate }\left(\mathrm{mm}^{3} / \mathrm{N} \cdot \mathrm{m}\right) \\ V & \text { wear volume }\left(\mathrm{mm}^{3}\right) \\ F_{n} & \text { load }(\mathrm{N}) \\ f & \text { friction force }(\mathrm{N}) \\ L & \text { sliding distance }(\mathrm{m}) \\ \alpha & \text { percentage of direct metal contact area over total area under load }(\%) \\ \mu & \text { coefficient of friction } \\ A_{r} & \text { total actual area under load }\left(\mathrm{mm}^{2}\right) \\ \tau_{b} & \text { shear strength of soft metals }(\mathrm{MPa}) \\ \tau_{f} & \text { shear strength of lubricant film }(\mathrm{MPa}) \\ \delta_{s} & \text { compressive yield strength limit of the material }(\mathrm{MPa}) \\ \delta_{s f} & \text { yield limit of lubricant film }(\mathrm{MPa})\end{array}$




\section{References}

1. Kimura, T.; Shimizu, K.; Terada, K. Sliding wear characteristic evaluation of copper alloy for bearing. Wear 2007, 263, 586-591. [CrossRef]

2. Equey, S.; Houriet, A.; Mischler, S. Wear and frictional mechanisms of copper-based bearing alloys. Wear 2011, 273, 9-16. [CrossRef]

3. Xiao, J.K.; Zhang, W.; Liu, L.M.; Zhang, L.; Zhang, C. Tribological behavior of copper-molybdenum disulfide composites. Wear 2017, 384, 61-71. [CrossRef]

4. Oksanen, V.T.; Lehtovaara, A.J.; Kallio, M.H. Load capacity of lubricated bismuth bronze bimetal bearing under elliptical sliding motion. Wear 2017, 388, 72-80. [CrossRef]

5. Ünlü, B.S.; Atik, E. Evaluation of effect of alloy elements in copper based CuSn10 and CuZn30 bearings on tribological and mechanical properties. J. Alloys Compd. 2010, 489, 262-268. [CrossRef]

6. Esawi, A.M.K.; Farag, M.M. Carbon nanotube reinforced composites: Potential and current challenges. Mater. Des. 2007, 28, 2394-2401. [CrossRef]

7. Terrones, M. Carbon nanotubes: Synthesis and properties, electronic devices and other emerging applications. Int. Mater. Rev. 2005, 49, 325-377. [CrossRef]

8. Tjong, S.C. Recent progress in the development and properties of novel metal matrix nanocomposites reinforced with carbon nanotubes and graphene nanosheets. Mater. Sci. Eng. R Rep. 2013, 74, 281-350. [CrossRef]

9. Bakshi, S.R.; Lahiri, D.; Agarwal, A. Carbon nanotube reinforced metal matrix composites-A review. Int. Mater. Rev. 2010, 55, 41-64. [CrossRef]

10. Duan, G.; Fang, H.; Huang, C.; Jiang, S.; Hou, H. Microstructures and mechanical properties of aligned electrospun carbon nanofibers from binary composites of polyacrylonitrile and polyamic acid. J. Mater. Sci. 2018, 53, 15096-15106. [CrossRef]

11. Shirasu, K.; Yamamoto, G.; Hashida, T. How do the mechanical properties of carbon nanotubes increase? An experimental evaluation and modeling of the engineering tensile strength of individual carbon nanotubes. Mater. Res. Express 2019, 6, 055047. [CrossRef]

12. Mallikarjuna, H.M.; Ramesh, C.S.; Koppad, P.G.; Keshavamurthy, R.; Kashyap, K.T. Effect of carbon nanotube and silicon carbide on microstructure and dry sliding wear behavior of copper hybrid nanocomposites. Trans. Nonferrous Met. Soc. China 2016, 26, 3170-3182. [CrossRef]

13. Vol, R.M.; Chunfeng, D.; Xuexi, Z.; Dezun, W. ScienceDirect Fabrication of aluminum matrix composite reinforced with carbon. Rare Met. 2007, 26, 450-455.

14. Duan, B.; Zhou, Y.; Wang, D.; Zhao, Y. Effect of CNTs content on the microstructures and properties of CNTs/Cu composite by microwave sintering. J. Alloys Compd. 2019, 771, 498-504. [CrossRef]

15. Kim, K.T.; Cha, S.I.; Hong, S.H.; Hong, S.H. Microstructures and tensile behavior of carbon nanotube reinforced Cu matrix nanocomposites. Mater. Sci. Eng. A 2006, 430, 27-33. [CrossRef]

16. Huang, Z.; Zheng, Z.; Zhao, S.; Dong, S.; Luo, P.; Chen, L. Copper matrix composites reinforced by aligned carbon nanotubes: Mechanical and tribological properties. Mater. Des. 2017, 133, 570-578. [CrossRef]

17. López, G.A.; Mittemeijer, E.J. The solubility of C in solid Cu. Scr. Mater. 2004, 51, 1-5. [CrossRef]

18. Esawi, A.; Morsi, K. Dispersion of carbon nanotubes (CNTs) in aluminum powder. Compos. Part A Appl. Sci. Manuf. 2007, 38, 646-650. [CrossRef]

19. Jiang, L.; Fan, G.; Li, Z.; Kai, X.; Zhang, D.; Chen, Z.; Humphries, S.; Heness, G.; Yeung, W.Y. An approach to the uniform dispersion of a high volume fraction of carbon nanotubes in aluminum powder. Carbon 2011, 49, 1965-1971. [CrossRef]

20. Yoo, S.J.; Han, S.H.; Kim, W.J. A combination of ball milling high-ratio differential speed rolling for synthesizing carbon nanotube/copper composites. Carbon 2013, 61, 487-500. [CrossRef]

21. Lin, C.B.; Chang, Z.C.; Tung, Y.H.; Ko, Y.Y. Manufacturing and tribological properties of copper matrix/carbon nanotubes composites. Wear 2011, 270, 382-394. [CrossRef]

22. Rajkumar, K.; Aravindan, S. Tribological behavior of microwave processed copper-nanographite composites. Tribol. Int. 2013, 57, 282-296. [CrossRef]

23. Tsai, P.C.; Jeng, Y.R. Experimental and numerical investigation into the effect of carbon nanotube buckling on the reinforcement of CNT/Cu composites. Compos. Sci. Technol. 2013, 79, 28-34. [CrossRef] 
24. Deng, H.; Yi, J.; Xia, C.; Yi, Y. Mechanical properties and microstructure characterization of well-dispersed carbon nanotubes reinforced copper matrix composites. J. Alloys Compd. 2017, 727, 260-268. [CrossRef]

25. Laha, T.; Kuchibhatla, S.; Seal, S.; Li, W.; Agarwal, A. Interfacial phenomena in thermally sprayed multiwalled carbon nanotube reinforced aluminum nanocomposite. Acta Mater. 2007, 55, 1059-1066. [CrossRef]

26. Chen, B.; Kondoh, K.; Imai, H.; Umeda, J.; Takahashi, M. Simultaneously enhancing strength and ductility of carbon nanotube/aluminum composites by improving bonding conditions. Scr. Mater. 2016, 113, 158-162. [CrossRef]

27. Chen, X.; Tao, J.; Yi, J.; Li, C.; Bao, R.; Liu, Y.; You, X.; Tan, S. Balancing the strength and ductility of carbon nanotubes reinforced copper matrix composites with microlaminated structure and interdiffusion interface. Mater. Sci. Eng. A 2018, 712, 790-793. [CrossRef]

28. Esawi, A.M.K.; Morsi, K.; Sayed, A.; Gawad, A.A.; Borah, P. Fabrication and properties of dispersed carbon nanotube-aluminum composites. Mater. Sci. Eng. A 2009, 508, 167-173. [CrossRef]

29. Akbarpour, M.R. Analysis of Load Transfer Mechanism in $\mathrm{Cu}$ Reinforced with Carbon Nanotubes Fabricated by Powder Metallurgy Route. J. Mater. Eng. Perform. 2016, 25, 1749-1756. [CrossRef]

30. Yamamoto, G.; Shirasu, K.; Nozaka, Y.; Wang, W.; Hashida, T. Microstructure-property relationships in pressureless-sintered carbon nanotube/alumina composites. Mater. Sci. Eng. A 2014, 617, 179-186. [CrossRef]

31. Kalin, M.; Poljanec, D. Influence of the contact parameters and several graphite materials on the tribological behaviour of graphite/copper two-disc electrical contacts. Tribol. Int. 2018, 126, 192-205. [CrossRef]

32. Yamamoto, G.; Hashida, T.; Adachi, K.; Takagi, T. Tribological Properties of Single-Walled Carbon Nanotube Solids. J. Nanosci. Nanotechnol. 2008, 8, 2665-2770. [CrossRef] [PubMed]

33. Akbarpour, M.R.; Alipour, S.; Farvizi, M.; Kim, H.S. Mechanical, tribological and electrical properties of Cu-CNT composites fabricated by flake powder metallurgy method. Arch. Civ. Mech. Eng. 2019, 19, 694-706. [CrossRef]

34. Akbarpour, M.R.; Alipour, S.; Najafi, M. Tribological characteristics of self-lubricating nanostructured aluminum reinforced with multi-wall CNTs processed by flake powder metallurgy and hot pressing method. Diam. Relat. Mater. 2018, 90, 93-100. [CrossRef]

35. Jin, Y.; Shi, G. Mechanism of Friction and Wear; Zhejiang University Press: Hangzhou, China, 1992.

(C) 2019 by the authors. Licensee MDPI, Basel, Switzerland. This article is an open access article distributed under the terms and conditions of the Creative Commons Attribution (CC BY) license (http://creativecommons.org/licenses/by/4.0/). 